https://helda.helsinki.fi

Snow cover is a neglected driver of Arctic biodiversity loss

Niittynen, Pekka

2018-10-22

Niittynen , P , Heikkinen , R K \& Luoto , M 2018 , ' Snow cover is a neglected driver of Arctic biodiversity loss ' , Nature Climate Change , vol. 8 , no. 11 , pp. 997-1001 . https://doi.org/10.1038/s41558-018-0311

http://hdl.handle.net/10138/322024

https://doi.org/10.1038/s41558-018-0311-x

acceptedVersion

Downloaded from Helda, University of Helsinki institutional repository.

This is an electronic reprint of the original article.

This reprint may differ from the original in pagination and typographic detail.

Please cite the original version. 


\section{Snow cover is a neglected driver of Arctic biodiversity loss}

2

3 Pekka Niittynen $^{1 *}$, Risto K. Heikkinen ${ }^{2}$, Miska Luoto ${ }^{1}$

4

$5{ }^{1}$ University of Helsinki, Department of Geosciences and Geography, P.O. Box 64, (Gustaf 6 Hällströmin katu 2a), FI-00014, Finland 7

$8 \quad{ }^{2}$ Finnish Environment Institute, Natural Environment Centre, P.O. Box 140, FI-00251 Helsinki, 9 Finland

10

$11 *$ Corresponding author, email: pekka.niittynen@helsinki.fi 12 
14 Snow has far-reaching effects on ecosystem processes and biodiversity in high-latitude 15 ecosystems, but have been poorly considered in climate change impact models ${ }^{1,2}$. Here, to

forecast future trends in species occurrences and richness, we fitted species-environment models with temperature data from three climate scenarios and simulated up to a $40 \%$ decrease in snow cover duration (SCD) $)^{3}$. We used plot scale data on 273 vascular plant, moss and lichen species in 1200 study sites spanning a wide range of environmental conditions typical for mountainous Arctic landscapes (within $165 \mathrm{~km}^{2}$ ). Based on the models, a rise in temperature increased overall species richness and caused only one species to lose all suitable habitat. In contrast, a shorter SCD tempered the effect of increasing temperature on species richness and led to accelerated rates of species' local extinctions after a tipping point at $20-30 \%$ SCD decrease. All three species groups showed similar extinction rates but contrasting species richness responses. Our simulations indicate that future biodiversity patterns in Arctic regions are highly dependent on the evolution of snow conditions. Climate impact models that ignore the effects of snow cover change may provide biased biodiversity projections, with potentially erratic implications for Arctic nature conservation planning.

\section{On-going and projected climate change is most forceful in high latitudes, causing the Arctic to} warm up at twice the global rate ${ }^{2,4}$. Research on Arctic climate change impacts has mostly focused on temperature changes alone, describing the climate change induced turnover of species and the associated ecosystem impacts, such as changes in land-surface albedo and soil carbon balance ${ }^{5,6}$. However, as the climate change in the Arctic is most prominent for winter months ${ }^{4}$, these regions may face important alterations in snow conditions including a 10-40\% decrease in snow cover duration (SCD) by $2050^{2,3}$. Recent snow cover dynamics have already led to major changes in Arctic ecosystems $s^{2,3,7}$, and further alterations in snow cover may promote changes in vegetation with substantial feedbacks on global climate ${ }^{5,7}$. However, the uncertainties included in the global 
climate models lead to high spatial heterogeneity in the projected trends for precipitation and snow $^{2,7,8}$. Furthermore, topographical heterogeneity causes strong local decoupling of SCD from regional climate ${ }^{9,10}$ suggesting that snow responses to climate warming may diverge notably in rugged terrain.

For biotic communities, snow is one of the most important controls on growing conditions ${ }^{9}$ and Arctic and alpine plant species are strongly affected by snow cover ${ }^{11,12}$. Snow accumulates unevenly in topographically complex landscapes, resulting in heterogeneous snow cover duration patterns ${ }^{10}$. This enables the regional co-occurrence of a wide range of species with different ecological requirements ${ }^{11}$. Despite the fundamental importance of snow, the consideration of the impacts of snow cover change is surprisingly lacking in climate impact models of tundra vegetation and is a major research gap acknowledged by the Arctic Monitoring and Assessment Programme ${ }^{2}$. By ignoring the changes in snow cover alongside temperature, most species-climate impact models dismiss an obvious mechanistic pathway of how climate change will alter Arctic and alpine ecosystems ${ }^{1,13,14}$. Here, in order to improve the understanding of the sensitivity of Arctic ecosystems to both snow cover and temperature changes, we utilized fine-scale observational information of snow cover dynamics linked with summer temperature data and the plot-scale occurrences of 273 vascular plant, moss, and lichen species in a comprehensively studied landscape (165 km²; 1200 study sites; Fig. 1). We examined the role of snow on biodiversity change under a warming climate by modelling the responsiveness and vulnerability of the study species to the separate and joint changes in temperature and snow cover duration. 

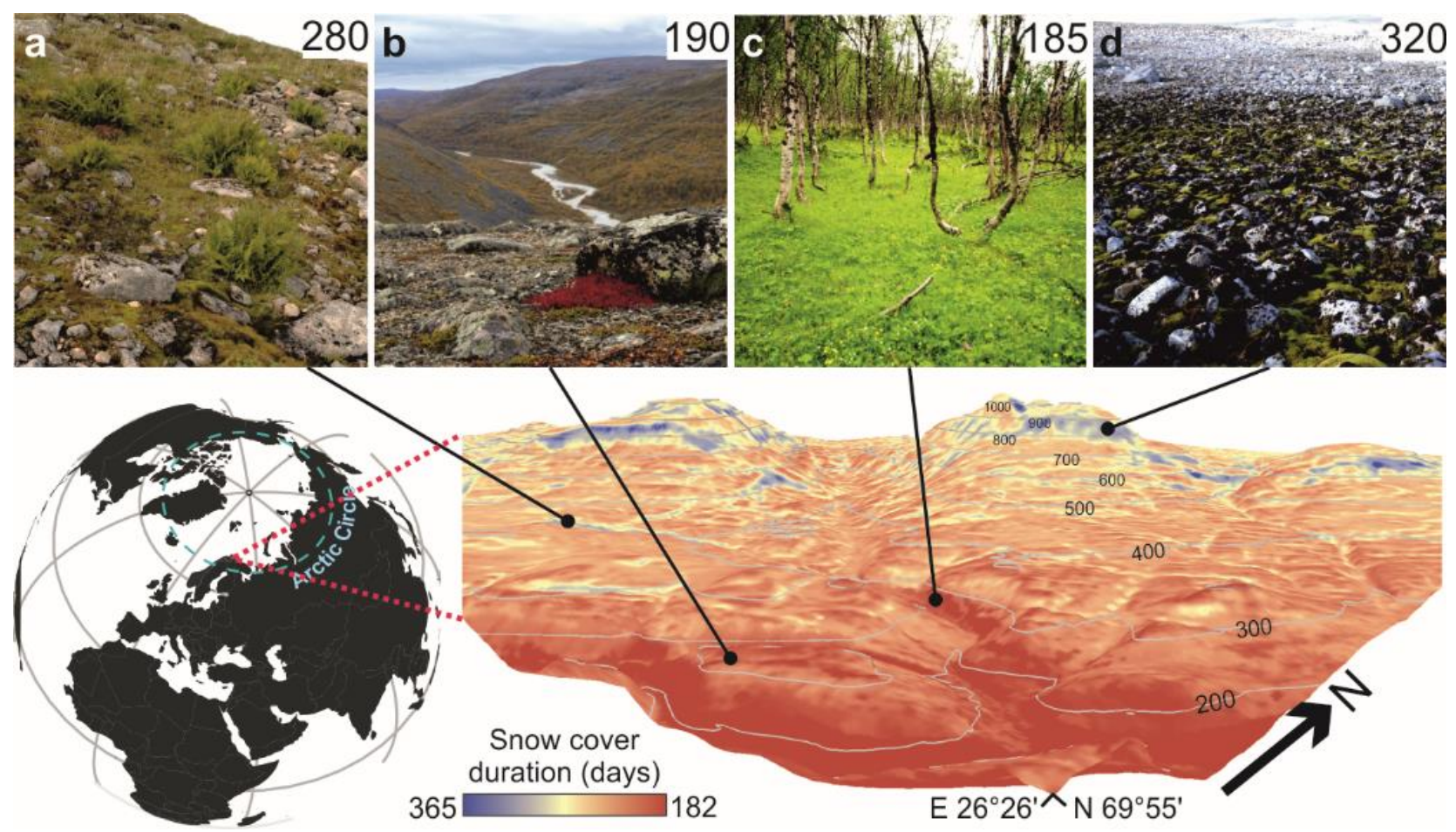

Figure 1. The study area and example habitats along the snow cover duration gradient. The study area in Northern Norway contains large elevational and snow cover duration gradients providing a wide spectrum of different habitats from early melting sub-arctic birch forests (c) and wind-blown lichens heaths (b) to forb-rich meadows (a) and moss-dominated snowbeds (d). Numbers in photographs indicate the length of snow cover duration in current climate for each of the habitats.

We mapped SCD and modelled the distributions of the 273 studied species at a $30-\mathrm{m}$ spatial resolution sufficient to capture the patchy nature of Arctic snow cover and vegetation patterns in our study area (Note S1). A spatially continuous and temporally comprehensive snow cover duration map was constructed based on in-depth analysis of 135 fine-scale satellite images (Landsat TM5, ETM7, and OLI8) spanning over 33 years ${ }^{12}$. To determine the key species-environment relationships, we used species distribution models (SDM) including the current temperature (baseline climate of 1981-2010) and snow conditions, while also controlling for the effects of five other environmental predictors known to be important for plants ${ }^{15}$, namely potential incoming radiation, topographic wetness index, slope angle, surface soil quality, and soil edaphic conditions. Using the SDMs calibrated for presentday relationships, we projected the species distributions for the year 2050 by developing four temperature projections (no change, and forced by Representative Concentration Pathway (RCP) scenarios 2.6, 4.5, and 8.5), nine SCD scenarios (no change and eight descending steps from 5\% down 
to $40 \%$ decrease in SCD, matching the range of recent snow cover projections ${ }^{3}$ ), and all possible combinations between these two groups of scenarios resulting in a total of 36 combinations. The temperatures were projected for period of 2040-2069 and averaged over 23 CMIP5 climate simulations ${ }^{16}$. Each species was modelled separately but as a final step we stacked the single-species predictions ${ }^{17}$ to examine how changing SCD and temperature affect overall species richness.

The species distribution models showed good average model fit $(\mathrm{AUC}=0.873$; TSS $=0.645)$ and cross-validated predictive performance $(\mathrm{AUC}=0.756$; $\mathrm{TSS}=0.450)$ across the 273 studied species and nine modelling methods. Separate impacts of decreasing SCD (Fig. 2, column at the far left) and, in particular, increasing temperature (Fig. 2, upper row) both led to a higher average total species richness. However, with respect to projected species extinctions (i.e. total loss of suitable SCDtemperature space), notable differences emerged. Projections based on temperature increase alone show only one species to go extinct even with the highest greenhouse gas emissions scenario (RCP8.5). In contrast, decreasing snow cover led to a rapid acceleration of species extinctions when decrease in SCD exceeds 20\%, revealing a potentially important (and under current conditions hidden) tipping point in the Arctic biodiversity-climate change relationship (Fig. 3a-b). When the impacts of SCD and temperature change are considered jointly, asymmetric trends emerged. Most importantly, major decreases in SCD counteracted temperature effects and tempered the increases in total species richness resulting from warming summers (Fig. 2). In contrast, accelerating species extinction trends along the SCD gradient were relatively insensitive to increasing temperature; the projected trends were of largely similar magnitude irrespective of the greenhouse gas emissions scenario (Fig. 3a). Moreover, projected trends were similar for each of the taxonomic groups resulting in ca. $15 \%$ extinction rate among the study species under the most extreme SCD scenario (Fig. 2). However, responses in species' biogeographic groups differed (Note S2). Extinction rate was higher 
106 in Arctic-alpine than boreal species (32\% and 12\%, respectively), and the difference was particularly 107 clear in vascular plants $(36 \%$ and $7 \%)$.

108

109 The projected trends of average species richness differed also between vascular plants, mosses, and

110 lichens. Vascular plant richness was promoted by higher temperatures but somewhat tempered by the 111 concurrent change in SCD (Fig 3c; Supplementary Fig S1 and S3). The moss species richness was 112 projected to increase in most of the 36 scenario combinations, reaching its maximum under conditions 113 where both temperature and SCD show maximal change (Fig 3d; Supplementary Fig S1 and S4). In 114 contrast to vascular plants and mosses, lichen species richness showed weaker response to decrease 115 in SCD. However, lichens appeared sensitive to the effects of temperature increase, showing the most 116 drastic decreases under the greatest changes in snow cover and temperature conditions of RCP8.5 117 (Fig 3e; Supplementary Fig S1 and S5).

118

119

120 


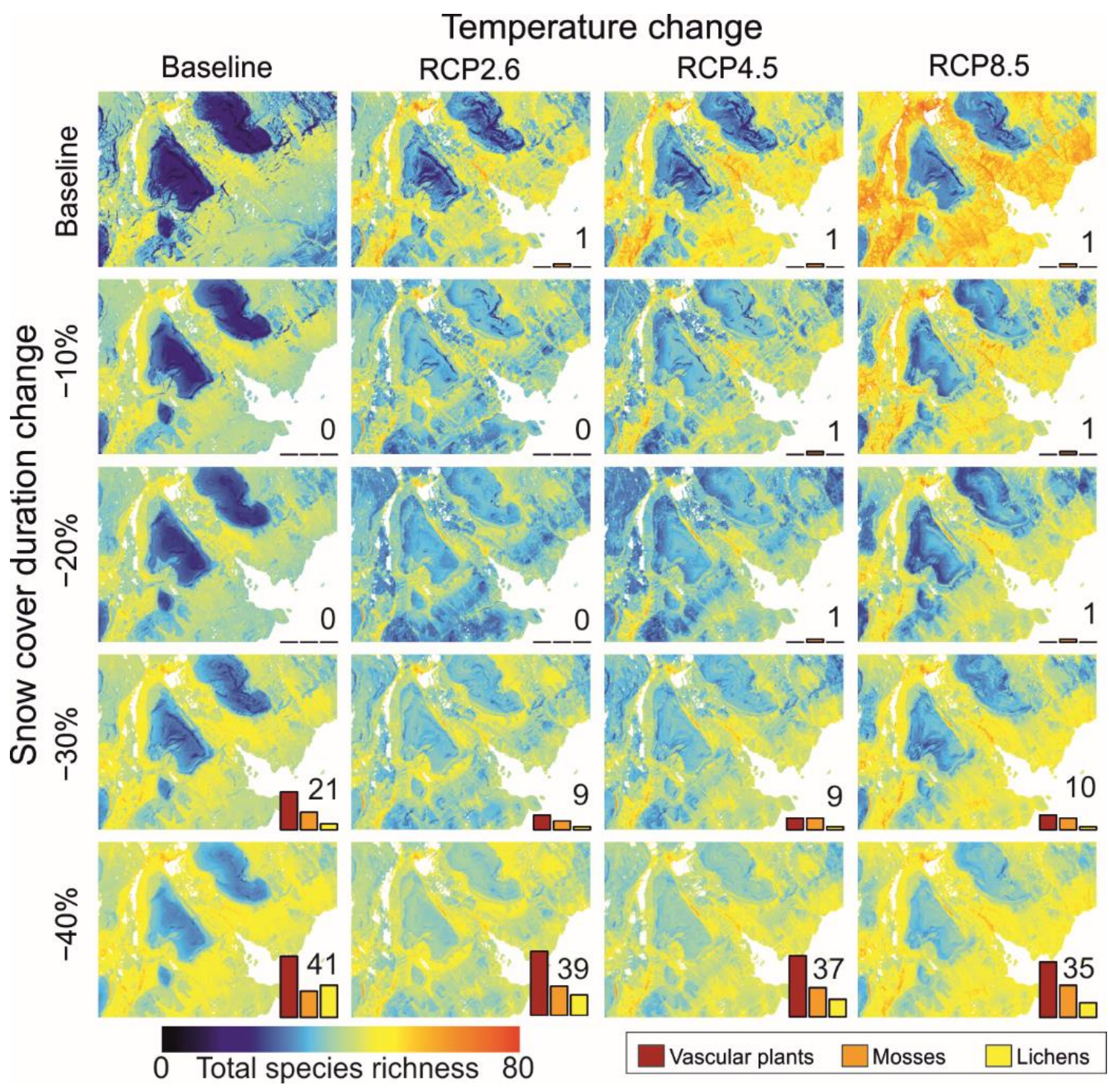

122 Figure 2. Projected species richness patterns (maps) and number of local extinctions (bars and 123 numbers). Predicted local species richness (summed probabilities of 273 individual species 124 distribution models) and number of extinctions (species losing all suitable habitat) by taxonomical 125 groups when conditions change from current climate to 19 different scenario combinations projected 126 to the year 2050. Areas below $400 \mathrm{~m}$ a.s.l. were excluded from the scenario maps to avoid prediction 127 to non-analogue climate space and extrapolation outside the model calibration data. 

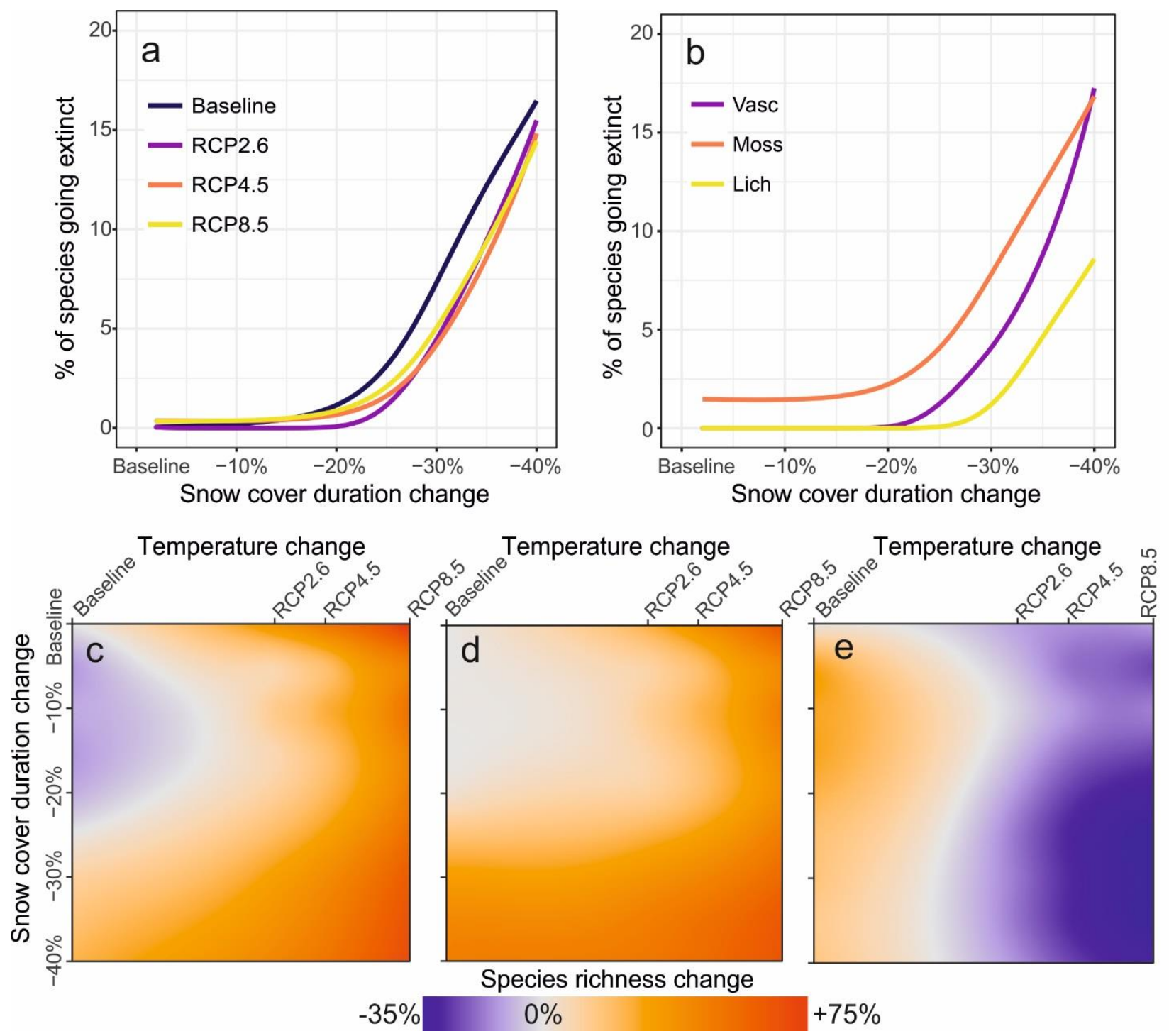

130 Figure 3. The evolution of the rate of extinctions and average species richness. The rate of local 131 extinction against changing snow cover duration under different temperature scenarios (a) and in the 132 three different taxonomic groups (b; greenhouse gas emissions scenario = RCP4.5). The evolution of 133 the average change in local species richness against changing snow cover duration and warming 134 summer temperatures (warming in RCP2.6 = 1.76; RCP4.5 = 2.19; RCP8.5 = 2.89) for vascular plants 135 (c), mosses (d), and lichens (e). 

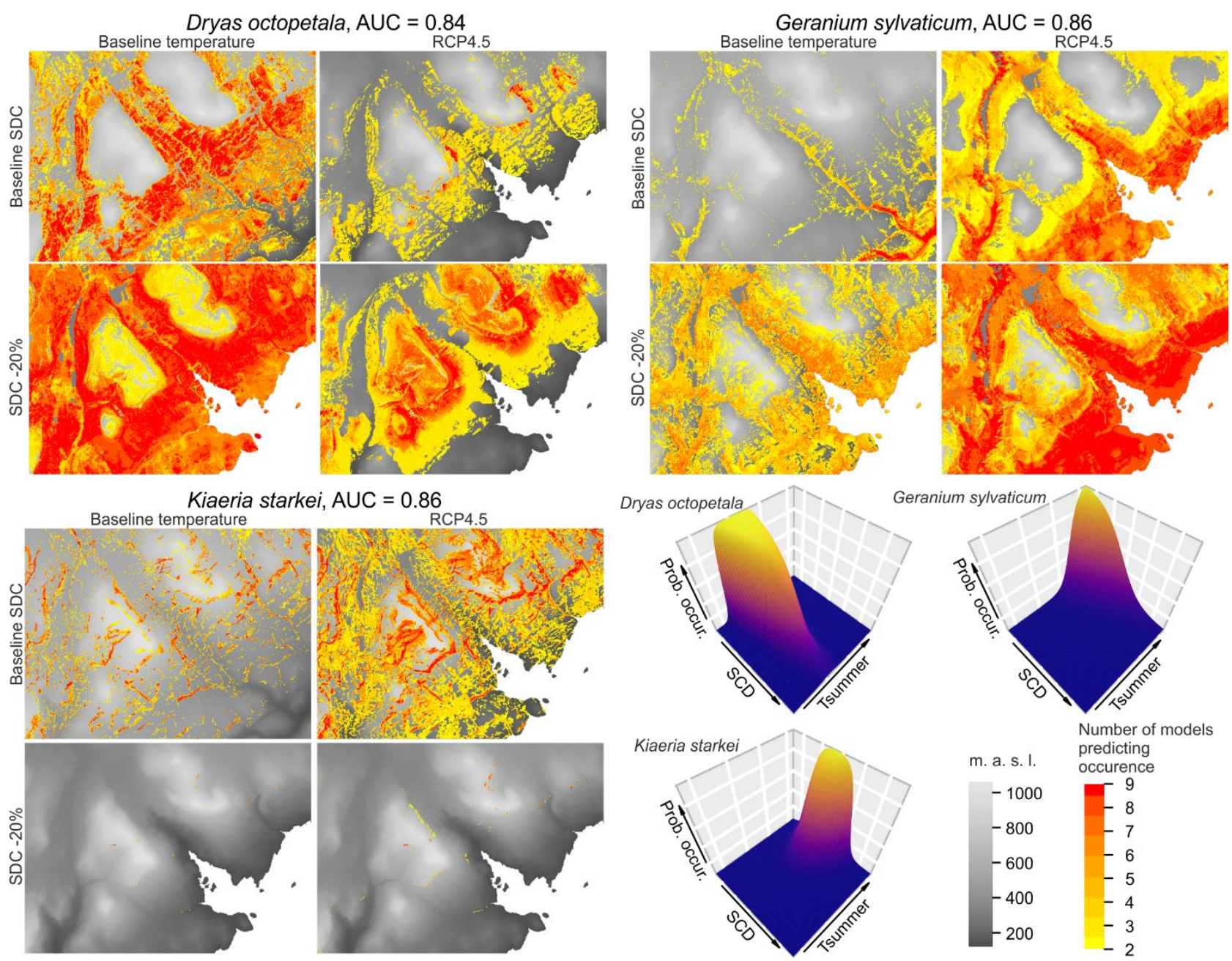

139 Fig 4. The occurrence predictions for three example species under current and future snow and summer temperature conditions. Dryas octopetala (Mountain avens) is a dwarf shrub inhabiting early melting dry mountain heaths; Geranium sylvaticum (Wood cranesbill) is a tall forb of relatively warm meadows; Kiaeria starkei (Starke's kiaeria moss) is a small moss and a snowbed specialist. The yellow-to-red color scale indicates the number of different modelling methods predicting an occurrence. The 3D response plots are constructed from generalized additive models. AUC (Area under curve) is an evaluation metric for binary models, with AUC $=1$ indicating perfect predictive performance.

Our models suggest that species with the highest modelled local extinction risk are threatened by a shortening of the snow season rather than solely temperature rise. In fact, many Arctic and alpine species may even benefit from the warming climate if the SCD remains stationary whereas other species show contrasting responses (see example species in Fig 4). Thus, species that are favored by warmer ambient temperatures are not always the same that can take advantage of a shorter snow season ${ }^{18}$. Importantly, the extinction rates in our results were three times higher among Arctic-alpine 
than boreal species. Most likely, boreal species projected to go extinct in our study area can survive

155 in other low productivity habitats. In contrast, snow-dependent Arctic-alpine species face the challenge of losing significant portions of their suitable habitats, not only in our study area, but also within their global distributions.

Tundra warming experiments have shown a general pattern of vascular plants benefiting from increased temperatures, mosses showing mixed responses, and lichens a declining trend ${ }^{19,20}$. Our

161 results widely agree with these patterns when considering trends in species richness. Vascular plant and moss richness increase as species expand their ranges upwards, while most lichen species retreat towards the mountain tops probably due to the competition between species groups ${ }^{21}$. The opposite trends in snow-driven extinction rates reflect the fact that the studied vascular plants and mosses include a higher proportion of snowbed species. Contrary, Arctic-alpine lichens mainly inhabit windswept heaths ${ }^{11}$, where decreasing snow cover has no further important impact on growing conditions.

The earlier research on the effects of changing snow cover is one-sided because only a few of the tundra experiments have manipulated the snow and temperature conditions in parallel ${ }^{22}$. Moreover, 171 there is a bias towards studies that have only simulated the increase in snow cover duration, in other words, an unlikely future climate ${ }^{22}$. However, our results agree with the earlier studies where tundra 173 vegetation has showed high sensitivity to changes in snow regime, manifesting via the direct or 174 indirect alteration of the physical, chemical, or biotic state of local habitat ${ }^{23-27}$. While manipulation 175 studies usually consider only a small number of species and habitats, our modelling study suggests that strong responses to changes in snow conditions may arise for a large number of species, resulting in rapid changes in species' distributions. This may give rise to development of novel species assemblages and ecological surprises depending on the ratio of temperature and snowpack change 
(Fig. S6). Furthermore, considering the differing trends of vascular, moss, and lichen richness shown here and knowing their dissimilar functional $\operatorname{traits}^{28}$, shifts in the balance between the species groups can pose significant consequences on the general functioning of Arctic and alpine ecosystems.

Drawing implications from our results to a wider context requires careful attention to at least three questions: (i) the uncertainties embedded in climate models, (ii) the high spatial variability of the snow projections, and (iii) topographical heterogeneity. Firstly, Callaghan et al. ${ }^{3}$ reviewed the progress in the development of global and regional snow cover change scenarios. They concluded that the limitations in General Circulation Models (GCM) may often hinder the construction of highquality projections for the Arctic snow cover change and that ensembles of the best performing GCMs are required to develop as realistic as possible regional projections (see also ${ }^{2,8,29}$ ). Thus, modelling many levels of potential SCD change is recommended to develop understanding of the alternative future directions of biodiversity change and potential tipping points. Secondly, observed snow trends and global snow projections hold remarkable spatial heterogeneity and thus exploiting our results requires consideration of predicted regional levels of SCD change. Shortening of the SCD is especially strong in maritime climates (up to 40\%), such as Fennoscandia, which are shifting from snow to rain dominated climate systems, even during the winters. In contrast, the predicted change is much lower in the most continental parts of Arctic Eurasia and America $(<10 \%)$ due to a combination of increasing winter precipitation and extremely cold winter temperatures. Thirdly, regions of complex topography contain a wide range of snow accumulation positions. Such landscapes may thus have an effective buffering capacity against the impacts of climate change. In turn, for relatively flat areas that do not have this safeguarding feature or harbor many snow-dependent species, the extinction rates may be different. 
Our predictions suggest that the future of Arctic vegetation is critically depends on the evolution of snow conditions. However, it should be acknowledged that snow has multiple pathways to alter Arctic biodiversity either by directly affecting the survival of the species or by indirectly modifying the biogeochemical cycles or biotic interactions ${ }^{1,7,30}$. Thus, other aspects of snow climatology than SCD should be examined as well, because changes in rain-on-snow events and insulating capacity of snowpack, for example, may have important ecological impacts ${ }^{2}$.

The recent climate record of northernmost Fennoscandia shows a minor warming trend and a decrease in SCD (Note S3). These changes may be considered indicative of the changes to be expected during the 21 st century. On one hand, while changes in temperature and snow conditions have the potential to increase plot-scale species richness, the shortening of the snow season may wipe out a remarkable

214 proportion of the Arctic-alpine species pool. On the other hand, if changes in snow cover duration 215 remain moderate, landscapes characterized by a wide SCD gradient may buffer the species loss induced by rising temperatures, even under the most severe warming. Future study efforts should be invested into examining snow-species-interactions and the climate sensitivity of snow cover.

218 Increased attention should also be targeted to the relatively high uncertainty in snow projections as 219 this vagueness is further transmitted into models of Arctic and alpine ecosystems. Our study offers a strong remark on how insufficient acknowledgement of the diverse impacts of spatio-temporally varying snow cover have more critical consequences for climate change-biodiversity models than has previously been considered.

\section{References (Main text)}

2251 Callaghan, T. V. et al. Multiple Effects of Changes in Arctic Snow Cover. Ambio 40, $32-45$ (2011).

2 AMAP. Snow, Water, Ice and Permafrost in the Arctic (SWIPA) 2017. 269 (Oslo, Norway, 2017). 
2293 Callaghan, T. V. et al. The Changing Face of Arctic Snow Cover: A Synthesis of Observed 230 and Projected Changes. Ambio 40, 17-31 (2011).

2314 Hartmann, D. L. et al. in Climate Change 2013: The Physical Science Basis. Contribution of Change (eds T.F. Stocker et al.) (Cambridge University Press, 2013).

5 Pearson, R. G. et al. Shifts in Arctic vegetation and associated feedbacks under climate change. Nat. Clim. Chang. 3, 673-677 (2013).

6 Hobbie, S. E., Schimel, J. P., Trumbore, S. E. \& Randerson, J. R. Controls over carbon storage and turnover in high-latitude soils. Global Change Biol. 6, 196-210 (2000).

7 Bokhorst, S. et al. Changing Arctic snow cover: A review of recent developments and assessment of future needs for observations, modelling, and impacts. Ambio 45, 516-537 (2016).

8 Bintanja, R. \& Andry, O. Towards a rain-dominated Arctic. Nature Clim. Change 7, 263-267 (2017).

9 Zhang, T. J. Influence of the seasonal snow cover on the ground thermal regime: An overview. Rev. Geophys. 43, RG4002 (2005).

10 Liston, G. E. \& Elder, K. A distributed snow-evolution modeling system (SnowModel). Journal of Hydrometeorology 7, 1259-1276 (2006).

11 Billings, W. D. \& Mooney, H. A. Ecology of Arctic and Alpine Plants. Biol. Rev. Camb. Philos. Soc. 43, $481-529$ (1968).

12 Niittynen, P. \& Luoto, M. The importance of snow in species distribution models of arctic vegetation. Preprint at http://onlinelibrary.wiley.com/doi/10.1111/ecog.03348/full (2017).

13 Bokhorst, S. et al. Changing Arctic snow cover: A review of recent developments and assessment of future needs for observations, modelling, and impacts. Ambio 45, 516-537 (2016).

14 Ernakovich, J. G. et al. Predicted responses of arctic and alpine ecosystems to altered seasonality under climate change. Global Change Biol. 20, 3256-3269 (2014).

15 Mod, H. K., Scherrer, D., Luoto, M. \& Guisan, A. What we use is not what we know: environmental predictors in plant distribution models. J. Veg. Sci. 27, 1308-1322 (2016).

16 Taylor, K. E., Stouffer, R. J. \& Meehl, G. A. An overview of CMIP5 and the experiment design. Bull. Amer. Meteorol. Soc. 93, 485-498 (2012).

17 Guisan, A. \& Rahbek, C. SESAM - a new framework integrating macroecological and species distribution models for predicting spatio-temporal patterns of species assemblages. $J$. Biogeogr. 38, 1433-1444 (2011).

18 Carlson, B. Z., Choler, P., Renaud, J., Dedieu, J. P. \& Thuiller, W. Modelling snow cover duration improves predictions of functional and taxonomic diversity for alpine plant communities. Ann. Bot. 116, 1023-1034 (2015).

19 Elmendorf, S. C. et al. Global assessment of experimental climate warming on tundra vegetation: heterogeneity over space and time. Ecol. Lett. 15, 164-175 (2012).

20 Lang, S. I. et al. Arctic warming on two continents has consistent negative effects on lichen diversity and mixed effects on bryophyte diversity. Global Change Biol. 18, 1096-1107 (2012).

21 Cornelissen, J. H. C. et al. Global change and arctic ecosystems: is lichen decline a function of increases in vascular plant biomass? J. Ecol. 89, 984-994 (2001).

22 Wipf, S. \& Rixen, C. A review of snow manipulation experiments in Arctic and alpine tundra ecosystems. Polar Res. 29, 95-109 (2010).

23 Aerts, R., Cornelissen, J. H. C. \& Dorrepaal, E. Plant performance in a warmer world: General responses of plants from cold, northern biomes and the importance of winter and spring events. Plant Ecol. 182, 65-77 (2006). 
24 Blume-Werry, G., Kreyling, J., Laudon, H. \& Milbau, A. Short-term climate change manipulation effects do not scale up to long-term legacies: effects of an absent snow cover on boreal forest plants. J. Ecol. 104, 1638-1648 (2016).

25 Bokhorst, S. F., Bjerke, J. W., Tommervik, H., Callaghan, T. V. \& Phoenix, G. K. Winter warming events damage sub-Arctic vegetation: consistent evidence from an experimental manipulation and a natural event. J. Ecol. 97, 1408-1415 (2009).

26 Kreyling, J., Haei, M. \& Laudon, H. Absence of snow cover reduces understory plant cover and alters plant community composition in boreal forests. Oecologia 168, 577-587 (2012).

27 Wipf, S. Phenology, growth, and fecundity of eight subarctic tundra species in response to snowmelt manipulations. Plant Ecol. 207, 53-66 (2010).

28 Cornelissen, J. H. C., Lang, S. I., Soudzilovskaia, N. A. \& During, H. J. Comparative cryptogam ecology: A review of bryophyte and lichen traits that drive biogeochemistry. Ann. Bot. 99, 987-1001 (2007).

29 Mankin, J. S. \& Diffenbaugh, N. S. Influence of temperature and precipitation variability on near-term snow trends. Clim. Dyn. 45, 1099-1116 (2015).

30 Wipf, S., Rixen, C. \& Mulder, C. P. H. Advanced snowmelt causes shift towards positive neighbour interactions in a subarctic tundra community. Global Change Biol. 12, 1496-1506 (2006).

\section{Material \& Methods (online-only)}

The study area $\left(165 \mathrm{~km}^{2}\right)$ is located in Finnmark, northern Norway ( $\mathrm{N} 70^{\circ} 0^{\prime}$ E $\left.26^{\circ} 14^{\prime}\right)$. The area consists of two mountain massifs (Rastigaisa, $1064 \mathrm{~m}$ a.s.l. and Geidnogaisa $1032 \mathrm{~m}$ a.s.l.) with steep valleys in between (lowest point $120 \mathrm{~m}$ a.s.1.), resulting in a large elevational gradient from mountain birch forests to almost barren mountain tops. The area provides a suitable study setting in regards to gathering intensive and multifaceted empirical field data along with developing effective speciesenvironment models due to the relatively short Euclidean distances between study sites paired with the areas extensive coverage of climatic space and a spectrum of habitats. Two specific useful features characterize our study area. 1) Considering species dispersal, the compactness of the study area facilitates a study system where the universal dispersal assumption can be plausibly employed as the default condition in the species distribution models. 2) Wide climatic space, in turn, reduces the risk that the projections of species' future distributions extend into non-analogous climates and enables the comprehensive modelling of species' niches. The main climatic characteristics of the study area 
311 (based on fine-scale gridded climate data set described in Aalto et al. ${ }^{31}$ ) are listed in supplementary 312 material table S1.

314 The climate station record from northern Fennoscandia $\left(>68^{\circ} \mathrm{N}\right)$ shows a significant increasing trend

315 for 3 out of 25 stations in summer temperature and a significant decreasing trend for 6 out of 16 in 316 snow cover duration during the 33-year study period (See supplementary materials Note S3 for more 317 details). On average, the snow cover duration has decreased by 17.3 days and summer temperature 318 increased by $0.76^{\circ} \mathrm{C}$ between 1984 and 2016 .

320 The study area lies at the southern margin of the circumpolar Arctic biome ${ }^{32}$. The forest line is formed 321 by mountain birch (Betula pubescens ssp. chzerepanovii) and it reaches elevations of 250-350 m a.s.1. 322 depending on slope aspect. The most dominant vegetation type is xeric tundra heath characterized by 323 several dwarf-shrub species such as crowberry (Empetrum nigrum ssp. hermaphroditum) and dwarf 324 birch (Betula nana) as the most dominant species. Depressions, small water channels, and other moist 325 habitats maintain forb-rich vegetation types and most water-logged wetlands are dominated by rushes 326 and willow thickets. In addition, snow cover duration creates its own gradient from lichen-covered 327 exposed sites to extremely late moss-dominated snowbeds (for more details, see Niittynen \& Luoto ${ }^{12}$ ). 328 The majority of the area is acidic Precambrian crystalline rock covered by glacial till, but the 329 mountain massifs are fringed by a thin layer of easily weathering shales (Hyolithus zone) that provide 330 a good substratum for more nutrient demanding or calcicolous species (e,g, Saxifraga ssp., Dryas 331 octopetala, Ranunculus sulphureus) ${ }^{33}$. The species pool consists of Arctic, alpine, and boreal species, 332 which makes it an interesting mix of species between the main biomes of the northern high-latitudes.

334 The vegetation dataset consists of occurrence records for 460 vascular plant, moss, and lichen taxa 335 observed in 1200 study sites. Each of the study sites consists of four $1 \mathrm{~m}^{2}$ vegetation plots situated 
five meters from the center of the site. Study sites were chosen in a semi-random manner in the field or beforehand using stratified sampling along the main environmental gradients. We aimed for a uniform spatial coverage and thus, every square kilometer of the study area includes at least four study sites. To reduce the risk of the effects of spatial autocorrelation in the modelling results, the minimum distance between study sites was 50 meters. The co-ordinates of the study sites were noted 341 using hand-held GPS-device in the field.

343 Vegetation sampling was conducted during July-September in three consecutive years (2014 - 2016). 344 Vascular plants are generally gaining most of the research effort in vegetation science, but here we 345 also focused on lichens and mosses (Bryophyta, not including liverworts and hornworts) in order to 346 thoroughly model the possible changes in the vegetation community. All the species were identified 347 at the species level with a few exceptions that cannot be distinguished reliably at the species level 348 (Alchemilla spp., Taraxacum spp., Cladonia chlorophaea -section, Lepraria spp.). Furthermore, 349 rock-dwelling lichens and mosses were excluded from the data as identification of these species often 350 requires DNA-techniques and these species are not dependent on the resources or physical conditions 351 of the soil, unlike vascular plants. With these exclusions, we ensured the full comparability between 352 the taxonomical groups. Nomenclature and species identification follows Hämet-Ahti et al. ${ }^{34}$ for 353 vascular plants, Laine et al. ${ }^{35}$, Hallinback et al. ${ }^{36,37}$, and Hedenäs and Hallinbäck ${ }^{38}$ for mosses, and 354 Stenroos et al..$^{39}$ for lichens.

356 We downloaded all available clear sky (less than 50\% cloud cover) Landsat TM 5, ETM 7 and OLI 3578 images covering the whole study area from March to October from 1984 to 2016 (total of 540 scenes) from USGS database (http: \learthexplorer.usgs.gov). The images were surface reflectance products, which were preprocessed (georeferencing and atmospheric corrections) by USGS ${ }^{40,41}$. For 
analysis, we selected images that were georeferenced correctly and cloudless over the whole study

361 area. The total number of suitable images was 135.

363 In our data, the snow cover duration (SCD) variable reflects the average length of the snow season 364 during the recent 33-year period and is produced pixel by pixel at the native spatial resolution of 365 Landsat $(30 \mathrm{~m})$. A time slice as long as this is analogous with the climatological normal period and, 366 moreover, is required to gather a sufficient number of suitable satellite images in an area frequently covered by clouds. The construction of SCD from satellite observations is a two-step process where the snowfall and melting day of years (DOY) were produced separately by generalized linear models (GLM). In general, in producing the pixel-based SCD we followed Macander et al. and Niittynen \& Luoto $^{12,42}$ with a few exceptions reported here. All the image processing was performed in statistical software $\mathrm{R}^{43}$ with Raster package ${ }^{44}$.

The individual cloud-free images were first converted to binary snow cover maps by calculating and thresholding a spectral index normalized difference snow index (NDSI; equation 1) ${ }^{45}$.

Equation 1: NDSI $=($ Green - SWIR $) /($ Green + SWIR $)$

376 Each pixel in an individual image was interpreted as snow if the NDSI value was over $0.4^{42}$. NDSI is a widely used spectral index in snow-related RS studies and is based on the relative difference in reflectance between green and shortwave infrared (SWIR) spectral bands. Waterbodies, that can also have high NDSI values, were later masked from the snow maps with a water layer digitized from high-resolution satellite images.

382 The snow melting DOY was determined pixel by pixel using binomial GLMs. Here all the images 383 from the autumn with new snow cover were excluded from the analysis, resulting in 124 images. 384 Every pixel had two strings of information that were passed as inputs for pixel-based GLMs: 1) a 
string of binary scores of snow occurrence (one score from each of the 124 images), and 2) a string of the corresponding DOY values. In the pixel-based GLMs, the binary snow scores were treated as a dependent variable and the DOYs as the predictor. After the model was fitted, it was used to predict the probability of snow occurrence for every possible DOY value from day 1 (January 1st) to day 273 (September 30th). We estimated the average snowmelt date to be the DOY in which the probability breaks the 0.5 probability threshold. If the probability stayed above the 0.5 for the whole sequence of DOYs, the pixel was determined as ever-snow.

The snowfall DOY was determined using the same principles as in determining the melting DOY. For the modelling, we selected the images from mid-August (DOY >=230) to October $(n=25)$ from which 11 images had a new snow cover. Then the GLM was fitted and used for predictions similarly as the melting DOY above. If the probability of snow occurrence stays above the 0.5 for the string of DOYs the pixel was determined as ever-snow. After the DOY melt $_{\text {and }}$ DOY $Y_{\text {new_snow }}$ were determined the total snow cover duration was calculated as:

$$
\text { Equation 2: } \mathrm{SCD}=\mathrm{DOY}_{\text {melt }}+\left(365-\mathrm{DOY}_{\text {new_snow }}\right)
$$

The SCD variable employed here has a good agreement with snow cover duration constructed with year-around soil temperature data from 175 microloggers (linear correlation $=0.873$ ) and snow patches observed from one fine scale (6-m resolution) satellite image (SPOT6; True skill statistics = 0.91). See supplementary materials Note S1 for further details of SCD validation process.

The Arctic snow cover duration is predicted to decrease by $10-40 \%$ before $2050{ }^{3}$. Therefore, we 407 simply reduce the observed pixel-based SCD by $5,10,15,20,25,30,35$ and $40 \%$. Thus, the absolute 408 change is smaller in sites with short SCD and bigger in late lying snow-beds. 
410 Summer temperatures were extracted from a gridded climate dataset that is presented by Aalto et al. ${ }^{31}$.

411 The dataset is based on monthly records of 942 climate stations in Fennoscandian countries (Finland, 412 Sweden and Norway) covering the period of 1981-2010, which were then interpolated with 413 generalized additive models using altitude, relative elevation, potential incoming radiation, and cover 414 of sea and lakes as predictors. Due to our relatively compact study area, different climatic factors are 415 strongly correlated with each other (Spearman correlation coefficient $|>0.9|$ ). Therefore, we selected 416 only summer (June, July, and August) mean temperature (Tsummer) to be the representative variable 417 for all climatic factors. The Tsummer variable was then projected for period of 2040-2069 forced by 418 three Representative Concentration Pathway (RCP) scenarios 2.6, 4.5, and $8.5^{16,46}$. The projected 419 temperatures were averaged over 23 CMIP5 climate simulations ${ }^{16}$.

421 As we wanted to construct reasonable and ecological models for the study species we also included 422 environmental predictors - in addition to temperature and SCD variables - that are known to have 423 important effects on vegetation in our study area ${ }^{15,47}$. No model-selection was made, i.e. all models 424 were forced to have the same predictor variables, ensuring that the models were fully comparable. To 425 capture the impacts of local environment, we employed five environmental predictors to represent 426 the main physical and chemical gradients: potential incoming radiation (RAD), topographic wetness 427 index (TWI), slope (SLOPE), surface soil quality (SOILQ), and soil edaphic conditions (EDAP). 428 Summary statistics for predictor variables are provided in supplementary materials (Table S2 and 429 Table S3). The nine SCD and four Tsummer scenarios combined produced a total number of 36 430 different models.

432 RAD, TWI, and SLOPE were derived from a 10-m resolution digital elevation model (DEM) [data 433 portal of Norwegian Mapping Authority (http://data.kartverket.no/download/)]. The potential annual 434 direct solar radiation was calculated $(\mathrm{MJ} / \mathrm{cm}-2 / \mathrm{y}-1)$ by using the equations of McCune and Keon 
assuming clear sky conditions ${ }^{48}$. SAGA Wetness index (hereafter TWI) is a modification of traditional topographical wetness index ${ }^{49}$ and was selected over the traditional as it mimics water flow patterns more realistically in flat areas ${ }^{50}$. The DEM was preprocessed by filling sinks ${ }^{51}$ and then used to calculate the specific catchment area and slope required by the TWI algorithm. SLOPE is the local slope angel in degrees. SOILQ represents the surface soil quality with five soil classes: peat, fluvial sediments, glacial till, bolder field, and bare rock. SOILQ is based on interpretation of fine-scale 441 aerial and satellite images (resolutions of $0.5-1.4 \mathrm{~m}$ ) verified with field surveys. EDAP represents 442 the nutritional status of the bedrock and was calculated as the downhill Euclidean distance to the shale 443 belt (the only base-rich rock type in the area) scaled from zero to 100. Areas located on the shale belt 444 were valued at 100 and areas uphill from shale belt or outside the area where the shale belt drains 445 were set to zero. The geological data were downloaded from the bedrock geology database maintained 446 by Geological Survey of Norway (http://geo.ngu.no/kart/berggrunn/). Values of predictors were 447 extracted for study points from original rasters but spatial predictions were conducted at $30 \mathrm{~m}$ spatial 448 resolution (as in Landsat images), and thus, variables were resampled to $30 \mathrm{~m}$ resolution using bilinear 449 interpolation (with the exception of the nominal variable SOILQ, in which case class with maximum 450 area aggregation was used).

452 Only species with at least 8 presence sites were included in the analyses: 273 species in total (132 453 vascular plants, 71 mosses, and 70 lichens). The binary distributions of individual species were 454 modelled using nine modelling methods implemented in Biomod2 modelling framework in $\mathrm{R}$ 455 modelling environment (generalized linear model = GLM; generalized additive models = GAM; 456 multiple adaptive regression splines = MARS; flexible discriminant analysis = FDA; classification 457 tree analysis $=\mathrm{CTA}$; generalized boosted method $=\mathrm{GBM}$, random forest $=\mathrm{RF}$; maximum entropy $=$ 458 MAXENT; artificial neural network $=\mathrm{ANN})^{52}$. The model parameterization is described in the 
supplementary materials (Note S4). By using nine modelling methods we decreased the algorithm

460 based error as the methods handle the data in fundamentally different manners.

462 All nine modelling methods produced their own projections for each species and for each climatic scenario. The models provide the probability of the species to be present in a given cell which was then binarized by thresholding the probability with a level that maximizes the TSS-value of the predictions. After the modelling method-specific binary projections were produced, we built an ensemble prediction which judges that the species is present in a certain cell if at least five of the nine methods predicted a local occurrence. This ensemble-building rule is called majority voting and is often utilized in species distribution modelling studies in order to decrease the importance of a single modelling method ${ }^{53}$. A species was determined as regionally extinct if the ensemble model did not 470 predict any occurrences. All spatial predictions are projected with models using all the 1200 study 471 sites for calibration. In order to check the predictive performance of the models we used cross472 validation where the data was randomly split into calibration data (70\% of the data) with which the 473 model was fitted and then used to predict species occurrence to the withheld $30 \%$ of the data. This 474 procedure was repeated four times for each species, and in each round Area under curve (AUC) and 475 true skill statistics (TSS) were calculated for each species and modelling method separately ${ }^{54,55}$. These metrics are frequently used in SDM studies to measure and evaluate the predictive accuracy of the 477 binary predictions.

480 The authors are grateful for research support provided by the Academy of Finland (project no. 481 1286950), Kone foundation, and Societas pro Fauna et Flora Fennica. We thank A. Niskanen for her 
483 work.

\section{Author contributions}

P.N., M.L., and R.K.H. designed the research. P.N. collected the field and satellite data, performed

Competing interests

The authors declare no competing financial interests.

\section{Data availability} request.

31 Aalto, J., Riihimäki, H., Meineri, E., Hylander, K. \& Luoto, M. Revealing topoclimatic

\section{References (Material \& Methods)}

32 Virtanen, R. et al. Where do the treeless tundra areas of northern highlands fit in the global biome system: toward an ecologically natural subdivision of the tundra biome. Ecol. Evol. 6, 143-158 (2016).

33 Ryvarden, L. The vascular plants of the Rastigaissa area (Finnmark, Northern Norway). Acta Borealia 26, 1-56 (1969). 
Hämet-Ahti, L., Suominen, J., Ulvinen, T. \& Uotila, P. Retkeilykasvio (Field Flora of Finland). 3 edn, (Finnish Museum of Natural History, Botanical Museum, Helsinki, 1998).

Laine, J. et al. The Intricate Beauty of Sphagnum Mosses - a Finnish Guide to Identification. Vol. 2 1-191 (University of Helsinki, Department of Forest Sciences, 2011).

36 Hallinbäck, T., Lönnell, N., Weibull, H., Hedenäs, L. \& von Knorring, P. Nationalnyckeln till Sveriges flora och fauna. Bladmossor: Sködmossor - Blåmossor. Bryophyta: Buxbaumia Leucobryum., (ArtDatabanken, SLU, 2006).

Hallinbäck, T. et al. Nationalnyckeln till Sveriges flora och fauna. Bladmossor: Kompaktmossor - kapmossor. Bryophyta: Anoectangium - Orthodontium., (ArtDatabanken, SLU, 2008).

38 Hedenäs, L. \& Hallinbäck, T. Nationalnyckeln till sveriges flora och fauna, Bladmossor: Skirmossor-Baronmossor. Bryophyta: Hookeria-Anomodon. (ArtDatabanken, SLU, 2014).

39 Stenroos, S., Ahti, T., Lohtander, K. \& Myllys, L. Suomen jäkäläopas. (Finnish Museum of Natural History, Botanical Museum, Helsinki, 2011).

40 USGS. Product guide: Landsat 4-7 climate data record (cdr) surface reflectance. (Department of the Interior U.S. Geological Survey, 2017).

41 USGS. Product guide: Provisional Landsat 8 surface reflectance code (lasrc) product. (Department of the Interior U.S. Geological Survey, 2016).

42 Macander, M. J., Swingley, C. S., Joly, K. \& Raynolds, M. K. Landsat-based snow persistence map for northwest Alaska. Remote Sens. Environ. 163, 23-31 (2015).

43 R: A language and environment for statistical computing. R Foundation for Statistical Computing (Vienna, Austria, 2016).

44 Hijmans, R. J. raster: Geographic data analysis and modeling. - R package ver. 2.5-8. (2016).

45 Hall, D. K., Riggs, G. A. \& Salomonson, V. V. Development of methods for mapping global snow cover using Moderate Resolution Imaging Spectroradiometer data. Remote Sens. Environ. 54, 127-140 (1995).

46 Moss, R. H. et al. The next generation of scenarios for climate change research and assessment. Nature 463, 747-756 (2010).

47 Austin, M. P. \& Van Niel, K. P. Improving species distribution models for climate change studies: variable selection and scale. J. Biogeogr. 38, 1-8 (2011).

48 McCune, B. \& Keon, D. Equations for potential annual direct incident radiation and heat load. J. Veg. Sci. 13, 603-606 (2002).

49 Beven, K. J. \& Kirkby, M. J. A physically based, variable contributing area model of basin hydrology. Hydrological Sciences Bulletin 24, $43-69$ (1979).

50 Böhner, J. \& Selige, T. in SAGA - Analysis and Modelling Applications (eds J. Boehner, K.R. McCloy, \& J. Strobl) (Goettinger Geographische Abhandlungen, 2006).

51 Wang, L. \& Liu, H. An efficient method for identifying and filling surface depressions in digital elevation models for hydrologic analysis and modelling. Int. J. Geogr. Inf. Sci. 20, 193213 (2006).

52 biomod2: Ensemble Platform for Species Distribution Modeling v. R package version 3.3-7 (2016).

53 Thuiller, W., Lafourcade, B., Engler, R. \& Araujo, M. B. BIOMOD - a platform for ensemble forecasting of species distributions. Ecography 32, 369-373 (2009).

54 Allouche, O., Tsoar, A. \& Kadmon, R. Assessing the accuracy of species distribution models: prevalence, kappa and the true skill statistic (TSS). J. Appl. Ecol. 43, 1223-1232 (2006).

55 Fielding, A. H. \& Bell, J. F. A review of methods for the assessment of prediction errors in conservation presence/absence models. Environ. Conserv. 24, 38-49 (1997). 